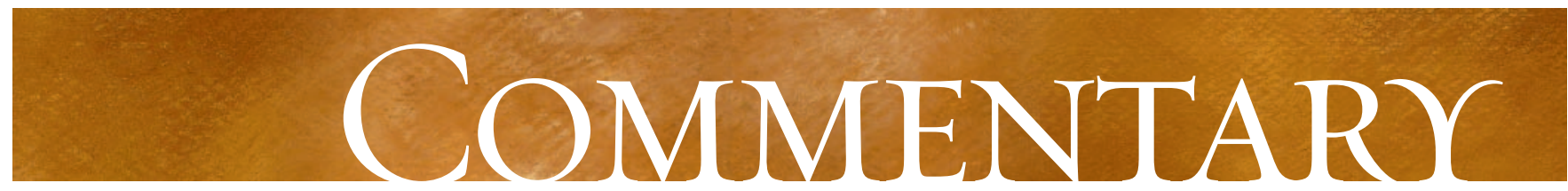

\title{
Health care use and risk of ovarian cancer: Is there a link?
}

\author{
Michael Fung-Kee-Fung, Melissa Brouwers, Thomas K. Oliver, Barry Rosen
}

$\infty \quad$ See related article page 94I

$\mathrm{T}$ he article by Abenhaim and colleagues in this issue presents an interesting case-control study that attempts to determine the risk of ovarian cancer associated with health care use by comparing the medical history of women with and without ovarian cancer. ${ }^{1}$ In this large study, 668 women with ovarian cancer and 72I healthy age-matched control subjects were interviewed about their demographic characteristics and their medical, dietary and family history during a 5-year period. Participants were also asked to complete a self-administered dietary questionnaire.

Abenhaim and colleagues report an increased risk of ovarian cancer among women who had no medical visits or pelvic examinations and who had no regular health care provider during the study period. These findings were most apparent among postmenopausal women. The authors rightfully detail the limitations of their study, especially with regards to study design, potential confounders and bias. They conclude that, although the exact mechanism is unknown, their findings suggest that a lack of regular health care is associated with an increased risk of ovarian cancer.

Ovarian cancer is a devastating disease, and there is considerable pressure on clinicians and policy-makers to identify and make available effective screening strategies and treatment options. However, the conclusion of the present study should be viewed cautiously. Acting on this conclusion in the form of clinical practice or policy change is premature.

One interpretation of this study is that receiving regular medical care from a primary health care provider in some way lowers the risk of ovarian cancer. However, this has not been shown to be the case. Indeed, there is expert agreement among the Canadian Task Force on the Periodic Health Examination, ${ }^{2}$ the US Preventive Services Task Force ${ }^{3}$ and the American College of Obstetricians and Gynecologists ${ }^{4}$ that, to date, no interventions have proven effective in the routine screening of asymptomatic low-risk women for ovarian cancer.

But what about the evidence? Consensus opinion from credible organizations is fine; however, there is a powerful method for synthesizing evidence that is often overlooked the systematic review. The strength of this methodology is the systematic strategy for locating, selecting, appraising and synthesizing all studies on a particular topic according to a set of specific criteria identified a priori. The sum total of the data tends to moderate individual study results that may have been due to chance, study design limitations, potential confounders, bias or misinterpretation of results.
Cancer Care Ontario's Program in Evidence-Based Care has taken the process of systematic review a step further by developing and refining the Practice Guidelines Development Cycle. ${ }^{5,6} \mathrm{~A}$ typical report from this program consists of a comprehensive systematic review of the evidence, an interpretation of the findings, expert consensus opinion and the resulting recommendations. External peer review is solicited from Ontario clinicians and administrators for whom the topic is relevant, to improve the quality of the document, to facilitate buy-in and to begin the process of knowledge translation and exchange. It is through this process that the evidence, resulting conclusions and recommendations for practice are considered in a balanced manner with consensus among practitioners who have clinically relevant expertise.

\section{Better patient outcomes would be seen if efforts were directed toward improving compliance with promising treatment modalities}

Indeed, 2 comprehensive systematic reviews by the Program in Evidence-Based Care's Gynecology Cancer Disease Site Group-one on screening postmenopausal women for ovarian cancer ${ }^{7}$ and the other on screening women at high-risk of ovarian cancer ${ }^{8}$ - have concluded that there is little value in the routine screening of these populations. These conclusions were well supported by clinicians in the practising community: $100 \%$ and $90 \%$ of external reviewers agreed with the interpretation of the evidence as presented in the 2 reports respectively. The findings from these 2 reviews are supported by the findings of other recent studies of ovarian cancer screening. ${ }^{9,10}$

Increasingly, the need to accurately interpret the totality of research findings from the medical scientific community, such as ovarian cancer risk and screening studies, is becoming 
a mandated requirement in the determination of health care utilization strategies, costs and best practices. An evidencebased approach is needed to determine the appropriate course of action for a given health care issue. This is important because it can identify options for cancer care that should be targeted for implementation. For example, although we do not yet know the most effective screening technique for ovarian cancer, we do know that intraperitoneal chemotherapy has been found to improve survival among patients in randomized clinical trials and is a treatment option that warrants targeted investigation. ${ }^{11}$ Yet, diffusion and uptake of this treatment option, despite the evidence base, is uneven. Better patient outcomes would be seen if efforts were directed toward improving compliance with promising treatment modalities, rather than trying to advance practice in areas where the totality of evidence to date suggests there is no benefit.

The conclusions from the study by Abenhaim and colleagues, although interesting, need to be considered within the larger evidentiary foundation upon which the issue of ovarian cancer risk and screening will one day be determined. We certainly do not object to women receiving yearly medical and pelvic examinations by qualified health care practitioners; however, the utility of this intervention should not be misinterpreted as a strategy to reduce the risk of ovarian cancer.

This article has been peer reviewed.

Michael Fung-Kee-Fung is Chair of the Gynecology Cancer Disease Site Group, Cancer Care Ontario, and is with the Department of Obstetrics, Gynecology and Newborn Care, The Ottawa Hospital-General Campus, Ottawa, Ont.; Melissa Brouwers is Director and Thomas Oliver is Gynecology Cancer Research Coordinator of the Program in Evidence-Based Care, Cancer Care Ontario, and both are with the Department of Clinical Epidemiology and Biostatistics, McMaster University, Hamilton, Ont; Barry Rosen is with the Society of Gynecologic Oncologists of Canada, and the Department of Gynecology Oncology, Princess Margaret Hospital, Toronto, Ont.
Competing interests: None declared.

Contributors: All of the authors contributed to the writing and revising of the article and approved the version to be published.

\section{REFERENCES}

I. Abenhaim HA, Titus-Ernstoff L, Cramer DW. Ovarian cancer risk in relation to medical visits, pelvic examinations and type of health care provider. CMAJ 2007; I76(7):94I-7.

2. Gladstone CQ. Screening for ovarian cancer. In: Canadian Task Force on the Periodic Health Examination: Canadian guide to clinical preventive health care. Ottawa: Health Canada; I994. p. 870-8I.

3. US Preventive Services Task Force. Screening for ovarian cancer: recommendation statement. US Preventive Services Task Force. Am Fam Physician 2005;71:759-62.

4. American College of Obstetricians and Gynecologists. ACOG committee opinion: number 280, December 2002. The role of the generalist obstetrician-gynecologist in the early detection of ovarian cancer. Obstet Gynecol 2002;100:I4I3-6.

5. Browman GP, Levine MN, Mohide EA, et al. The practice guidelines development cycle: a conceptual tool for practice guidelines development and implementation. $J$ Clin Oncol I995; 13:502-I2.

6. Browman GP, Newman TE, Mohide EA, et al. Progress of clinical oncology guidelines development using the Practice Guidelines Development Cycle: the role of practitioner feedback. J Clin Oncol I998;16:1226-31.

7. Fung MF, Bryson P, Johnston M, et al. Cancer Care Ontario Practice Guidelines Initiative Gynecology Cancer Disease Site Group. Screening postmenopausal women for ovarian cancer: a systematic review. J Obstet Gynaecol Can 2004;26:717-28.

8. Rosen B, Fung-Kee-Fung M, Elit L, et al. Cancer Care Ontario Gynecology Cancer Disease Site Group. Screening high-risk women for ovarian cancer. [evidence summary Report 4-6b]. Toronto: Cancer Care Ontario, 2004. Available: www.cancercare.on.ca/pdf/pebc4-6bf.pdf (accessed 2007 Feb 20).

9. Reynolds E, Moller K. A review and an update on the screening of epithelial ovarian cancer. Curr Probl Cancer 2006;30:203-32.

Io. Kyrgiou M, Tsoumpou I, Martin-Hirsch P, et al. Ovarian cancer screening. Anticancer Res 2006;26:4793-80I.

II. Elit L, Oliver TK, Covens A, et al. Intraperitoneal chemotherapy in the first-line treatment of women with stage III epithelial ovarian cancer: a systematic review with metaanalyses. Cancer 2007;109:692-702.

Correspondence to: Dr. Michael Fung-Kee-Fung, Department of Obstetrics, Gynecology and Newborn Care, The Ottawa HospitalGeneral Campus, 50I Smyth Rd., Ottawa ON KIH 8L6; mfung@ottawahospital.on.ca 